\title{
NDD.05. Tuberous sclerosis: clinical case report and literature review
}

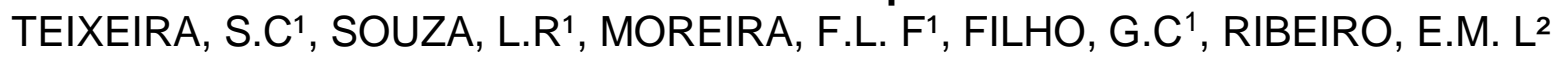

\section{1-Universidade Federal do Ceará \\ 2- Santa Casa de Misericórdia de Sobral *lucas.r.souza94@gmail.com}

Introduction: The tuberous sclerosis complex is a genetic disorder that affects cell proliferation and differentiation. It produces pleomorphic symptoms involving multiple organs and systems, like diffuse hamartomatosal lesions at the brain, eyes, liver and heart. Its prevalence is of one case over 10000 inhabitants and its incidence is of one over 6000 . There are many neurological findings, since they vary on the tubercles localization, but patients usually present epilepsy, cognitive deficits and gait abnormalities. Objectives: The present study aimed to describe a clinical case of tuberous sclerosis of a patient who has been treated during the neurology ward of the Santa Casa de Misericordia of Sobral Hospital (SSNC). Methods: CGTS, female, 22 years old, student, single. Presented, on March of 2008, brief and fast contractions on the left hand fingers, followed by a transitory palsy of the left arm, with complete and gradual recuperation of strength after 2 to 3 minutes. New crisis of the same pattern started to occur since then with a frequency of 1 to 2 episodes/week until recently. On February of 2010, she presented an abrupt paresthesia of the left upper limb and left hand contraction, followed by loss of conscience and tonic-clonic contractions, most evident on the left side of the body. After the crisis, she referred injury tongue injury, lethargy, dizziness, visual difficulty (1 minute) and moderate intensity headache, "warm" and pulsatile at the occipital region (30 minutes). She denies any other signs before the crisis nor sphincter liberation, sialorrhea, vomit and myalgia. After the first episode, she started having common headaches at the occipital region. About a month ago, she started having dysgeusia. A week ago, she presented brief and isolated hallux's dorsiflexion movements, with a frequency of 2 to 3 episodes/day, daily, and with no other associated symptom. She also refers brief muscular contraction on the medial side of her leg and paresthesia on the left side of the face in the area between the upper lip and the nose. Patient was born of natural childbirth, but presented ptosis at the left side until she completed 3 years old. When she was 1 year and 3 months old, she started walking. At neurological examination, patient had a preserved superior cortical function as well as her cranial nerves. Motricity, reflexes, sensibility, coordination and balance were also normal. At the physical examination, she showed the following cutaneous alterations: Hyperemiated malar region, hypomelanotic maculae with a diameter range between 1.5 and 3.0 centimeters on limbs and Shagreen's sign. Results: Tuberous sclerosis has a wide clinical presentation because it affects different tissues. Among the physical examination findings, cutaneous angiofibromas and hypomelanotic maculae can be normally observed at the gingiva. Also, cardiac rhabdomiomas, which are focal or diffuse and infiltrative benign tumors, can be normally found. Other characteristics of this complex are ocular abnormalities and cognitive deficit, but this one was not observed on this case. Conclusions: Since it has a wide range of clinical manifestations, it is important for medical professionals to understand and correctly diagnose patients with the tuberous sclerosis complex. Understanding the tuberous sclerosis complex and correctly diagnosing the tuberous sclerosis complex is essential for medical professionals. Many organs and systems can be affected from it and that lets it have such a wide range of clinical manifestations. There are many symptoms associated to this complex, but most of them are cutaneous and related to benign brain tumors.

TEIXEIRA, S.C.; SOUZA, L.R.; MOREIRA, F.L. F.; FILHO, G.C.; RIBEIRO, E.M. L. 2013. Tuberous sclerosis: clinical case report and literature review, p.34. In: Oriá, Reinaldo Barreto; Andrade, Geanne Matos de; Bruin, Veralice Meireles S. de. I International Symposium in Neuroscience Meeting [Blucher Neuroscience Proceedings n.1 v.1]. São Paulo: Blucher, 2014, http://dx.doi.org/10.5151/isnm-sine29 